Research Article

\title{
Effect of Deformation Parameters on Microstructure and Mechanical Properties of Internal Crack Healing in As-Cast 30Cr2Ni4MoV Steel
}

\author{
Yongxing Jiao $\mathbb{D}^{1},{ }^{1}$ Cunlong Zhou, ${ }^{1}$ Jiansheng Liu $\mathbb{D}^{2},{ }^{2}$ and Xuezhong Zhang ${ }^{2}$ \\ ${ }^{1}$ School of Mechanical Engineering, Taiyuan University of Science and Technology, Taiyuan 030024, Shanxi, China \\ ${ }^{2}$ School of Materials Science and Engineering, Taiyuan University of Science and Technology, Taiyuan 030024, Shanxi, China \\ Correspondence should be addressed to Jiansheng Liu; jiansliu@163.com
}

Received 27 October 2020; Revised 28 January 2021; Accepted 20 February 2021; Published 26 February 2021

Academic Editor: Gianfranco Palumbo

Copyright (C) 2021 Yongxing Jiao et al. This is an open access article distributed under the Creative Commons Attribution License, which permits unrestricted use, distribution, and reproduction in any medium, provided the original work is properly cited.

Crack defects seriously affected the quality of heavy forgings, which needed to be eliminated by forging process. In this study, the healing process of internal crack defects was studied under different deformation parameters. The internal crack was produced by drilling the sample of $30 \mathrm{Cr} 2 \mathrm{Ni} 4 \mathrm{MoV}$ steel and then compressing the sample with different deformation. The microstructure of the crack healing zone was observed using an optical microscope. Meanwhile, the static and dynamic mechanical properties of the crack healing zone were tested by room-temperature tensile tests and impact tests, respectively. The results showed that dynamic recrystallization (DRX) and grain growth were the main factors for internal crack healing. When the forging ratio (FR) was 1.5, the cracks at the corner of the void began to heal, which was caused by DRX. At FR 2.0, the DRX was completed and the center crack was completely healed. The tensile properties of crack healing zones were restored to more than $95 \%$ of the base material. As the FR increased to 2.2, the elongation increased slightly and the yield strength decreased slightly, which indicated that the grain growth played an important role in the plastic recovery and DRX played an important role in strength recovery. The dynamic mechanical properties of the crack healing zone gradually increased with the increase of deformation. Furthermore, the maximum value of impact toughness reached FR 2.0, and the recovery rate of impact toughness was above 96\%. When the deformation continues to increase, the grains grew up after DRX, which made the impact energy decrease.

\section{Introduction}

Due to the large size of heavy forgings, the void defects inevitably occur in the ingot during the casting process. The elimination of void defects can be divided into two stages: void closing and void healing. Void closure refers to the elimination of voids through deformation, which is basically based on the contact between the upper and lower surfaces of the void [1-3]. However, the internal cracks formed after void closure will seriously affect the mechanical properties of forgings. Only when the internal cracks are healed and the mechanical properties are restored can the void defects be considered to be completely eliminated [4]. Therefore, it is necessary to study the recovery process of internal cracks during hot deformation.
At present, the physical simulation and numerical simulation were mainly used in the research of internal crack healing $[5,6]$. Scholars have studied the evolution process of internal cracks from the perspectives of healing mechanism [7], healing methods [8], healing influencing factors [9], and establishment of determination methods [10]. Chen et al. $[11,12]$ studied void defects' evolution inside large forgings based on the numerical simulation and experimental verification. Zhang and Sun [13] pointed out that the healing of cracks has a great relationship with atomic diffusion and lattice diffusion by observing the evolution of cracks in the experimental process. Song and Wang [14] studied the effect of dynamic recrystallization (DRX) and grain growth mechanism on the internal cracks' healing and found that increasing deformation and holding time were beneficial to 
crack healing. Hosoi et al. [15] studied the evolution law of fatigue crack of SUS316 austenitic stainless steel and obtained that high-temperature deformation pressure was the main factor leading to crack closure. Zhang and Han [16] studied the microstructure evolution of 20 steel after hot deformation and heat treatment and found that the ferrite grains assembled along the boundary of the crack.

In addition to the study of the microstructure after crack healing, the recovery of mechanical properties was also studied. Xin et al. [17] found that the tensile properties of the material recovered completely when the internal cracks were healed by heat treatment, but the impact properties of the materials were only partially restored. Qiu et al. [18] discovered that the tensile properties of the material can be completely restored after the microstructure of the crack area is recovered, but the fatigue properties were only partially recovered. Wang et al. [19] analyzed the behavior of carbides precipitated along grain boundaries and found that carbides led to grain-boundary weakness and deteriorated the mechanical properties. Considering the complexity of the stress in the actual service process, the research on the recovery of static tensile properties and dynamic impact properties needs to be studied.

In this paper, the evolution process of cracks under high temperature and high pressure was studied. The DRX and grain growth in the healing zone were observed, and the high-temperature healing mechanism of internal cracks in the as-cast $30 \mathrm{Cr} 2 \mathrm{Ni} 4 \mathrm{MoV}$ was revealed. Meanwhile, the recovery of tensile strength under static load and impact property under dynamic load was measured by experiments. Finally, a new quantitative evaluation method for crack healing was established.

\section{Experimental Procedure}

The internal crack in the specimen was produced by compressing the artificial void. The size of the specimen is $150 \mathrm{~mm} \times 150 \mathrm{~mm} \times 120 \mathrm{~mm}$, and a $10 \mathrm{~mm}$ through-hole was drilled in the center of the specimen. The WHF (Wide Die Heavy Blow) drawing forging of $30 \mathrm{Cr} 2 \mathrm{Ni} 4 \mathrm{MoV}$ was carried out on a $500 \mathrm{t}$ hydraulic press, and the compression temperature was $1200^{\circ} \mathrm{C}$. The initial microstructure is shown in Figure 1. The compression process was divided into four passes. After each compression, the specimen was turned 90 degrees for the next compression. The forging ratios (FRs) were $1.1,1.5,1.8,2.0$, and 2.2, respectively. After the experiment, the central positions of the specimens were cut to observe the changes of the microstructure.

After the compression test, the metallographic sample was made by cutting, grinding, and polishing along the compression direction of the specimen by wire cutting. The crack healing area was in the middle of the observation sample, and the size of the sample was $15 \times 15 \times 15 \mathrm{~mm}$. The sampling is shown in Figure 2. By using the optical microscope (Zeiss Axis-10), the crack morphology was observed and the crack width was measured. Then, the samples were etched by a $4 \%$ nital and picric acid-saturated water solution. After etching for 3-5 minutes, the microstructure of the crack healing zone was observed using an optical microscope.

After crack healing, in order to observe the change of mechanical properties, the static tensile tests and dynamic load impact tests were implemented. In the tensile tests, the sampling diagram is shown in Figure 3(a). The length of the tensile sample was $96 \mathrm{~mm}$, the gauge dimension was $40 \mathrm{~mm}$, and the diameter was $\Phi 8 \mathrm{~mm}$, as shown in Figure 3(a). An electronic universal testing machine (Ag xpivs $100 \mathrm{kN}$ ) was used to carry out the tensile tests. The tensile rate was $2 \mathrm{~mm} /$ min. After the sample was broken, a $10 \mathrm{~mm}$ high fracture was cut by a line-cutting machine (DK7625P), and the fracture morphology was observed by means of an electron microscope (FEG-SEM).

In the impact tests, Charpy $\mathrm{V}$-notch samples with dimensions of $10 \mathrm{~mm} \times 10 \mathrm{~mm} \times 55 \mathrm{~mm}$ were taken from the crack healing area, as shown in Figure 3(b). The impact tests were carried out on a $300 \mathrm{~J}$ pendulum impact testing machine (JB-300) for at least three times for the same sample. After the impact tests, the fracture morphology was observed by means of an electron microscope (FEG-SEM).

\section{Results and Discussion}

3.1. Microstructure of the Crack Healing Zone. When the FR was 1.1, the microstructure of the center position is shown in Figure 4. Figures 4(a) and 4(c) are the grain structure magnified by 100 times, and Figures 4(b) and 4(d) are the grain structure of the same position at 200 times magnification. From Figure 4(a), the sharp corners appeared around the void and gradually closed from this position. Due to the small deformation, there were coarse primary grains around the void, and the grain size was $276.6 \mu \mathrm{m}$. As shown in Figure 4(b), the cracks formed around the voids pass through the middle of the grains. When observing the grain structure at other positions around the void, few DRX small grains appeared around the void, as shown in Figures 4(c) and $4(\mathrm{~d})$. The reason was that there were many defects and high energy in the void boundary, and atoms were easy to diffuse, which was conducive to the fluctuation of composition, energy, and structure. The coupling of these factors provided sufficient conditions for the nucleation and growth of recrystallization [20]. Therefore, there were small DRX grains on the boundary, which played an important role in void healing.

Figure 5 shows the microstructure of the crack healing zone at FR 1.5. As shown in Figure 5(a), the void size decreased with the increase of deformation. The sharp corner of the void had been closed, and an obvious crack had been formed. The distribution of grains around the crack was more uniform than that of FR 1.1, and the grain size was $73.27 \mu \mathrm{m}$. When the sample was magnified 200 times, the grain morphology around the crack is shown in Figure 5(b). There were a lot of DRX grains around the crack. In addition, the new small DRX grains formed a healing band, which indicated that DRX was the main mechanism of crack healing. The microstructure at the farthest position from the void is shown in Figure 5(c). The voids were completely closed, and the original coarse structure was replaced by 


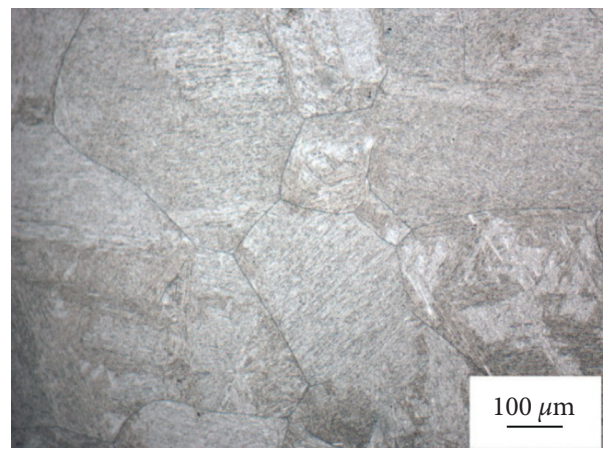

Figure 1: The initial microstructure of $30 \mathrm{Cr} 2 \mathrm{Ni} 4 \mathrm{MoV}$ steel.

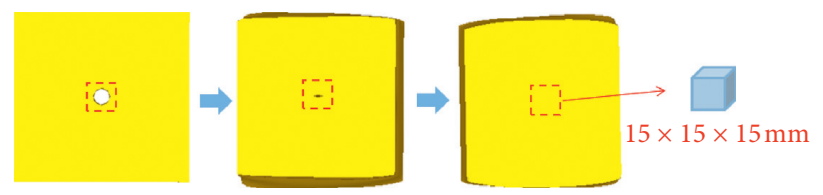

Figure 2: Sampling diagram of the metallographic specimen (unit: $\mathrm{mm}$ ).
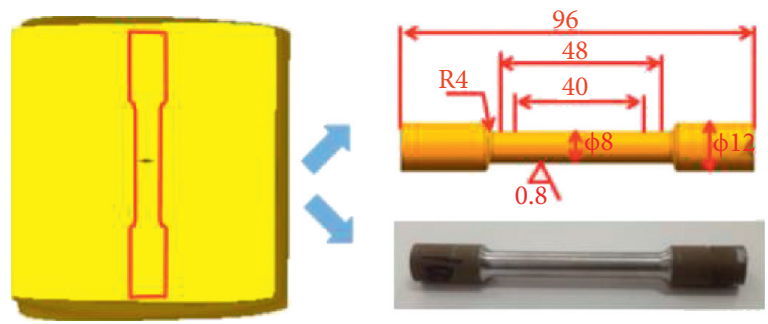

(a)

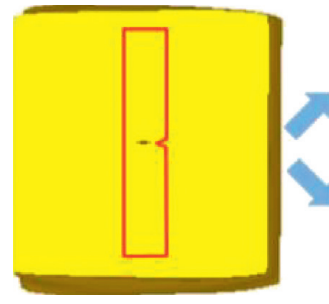

(b)

Figure 3: (a) Sampling diagram of the tensile sample. (b) Sampling diagram of the impact sample (unit: $\mathrm{mm}$ ).

DRX grains. Due to the increase of deformation, the cracks formed after the void was closed appeared to be in a discontinuous phenomenon. When the crack break was magnified to 200 times, it can be seen from Figure 5(d) that the crack was interrupted due to the growth of recrystallized grains. Finally, the original crack changed into a new grain boundary, which promoted the final healing of the crack and gradually became consistent with the matrix structure.

As the FR increases to 1.8 , the microstructure evolution around the crack is shown in Figure 6. In Figure 6(a), the coarse grain structure was refined with the increase of deformation, and the grain size was $58.01 \mu \mathrm{m}$. With the increase of the crack healing degree, continuous cracks were gradually broken by newly formed DRX grains. When the discontinuous crack was magnified 200 times (Figure 6(b)), there were microvoids in the crack healing zone, which will seriously affect the mechanical properties of the material. Therefore, it is necessary to eliminate the microvoid defects by increasing the deformation.

Figure 7 presents the microstructure of the crack healing zone at FR 2.0. As shown in Figure 7(a), the DRX grains around the crack had grown up and connected with the surrounding matrix grains. The grain size was $46.28 \mu \mathrm{m}$.
With the FR increasing to 2.0, the internal cracks formed by void closure completely disappeared, and the DRX grains gradually grew and became uniform. Due to the growth of DRX grains, the cracks completely disappeared and the original cracks developed into new grain boundaries, as shown in Figure 7(b). The grain size in the crack healing zone was relatively uniform, which indicated that the fine grains in the crack zone grew up or were swallowed up by the large grains near the crack. At the same time, the microvoids on the crack disappeared, so it can be considered that the crack was completely healed.

With the increase of FR to 2.2, the microstructure of the crack healing zone is shown in Figure 8. In Figure 8(a), there was no crack in the center of the specimen, and the DRX grains had grown up with an average grain size of $64.71 \mu \mathrm{m}$. From the above analysis, it can be known that the greater the deformation was, the better the crack healing was. The main mechanism of healing was that DRX promotes the crack healing, and the grain growth makes the grain uniform. As shown in Figure $8(\mathrm{~b})$, the grain size increased obviously because the recrystallized grains grew gradually with the increase of deformation time. The increase of grain size will lead to the decrease of plasticity and strength. Therefore, for 


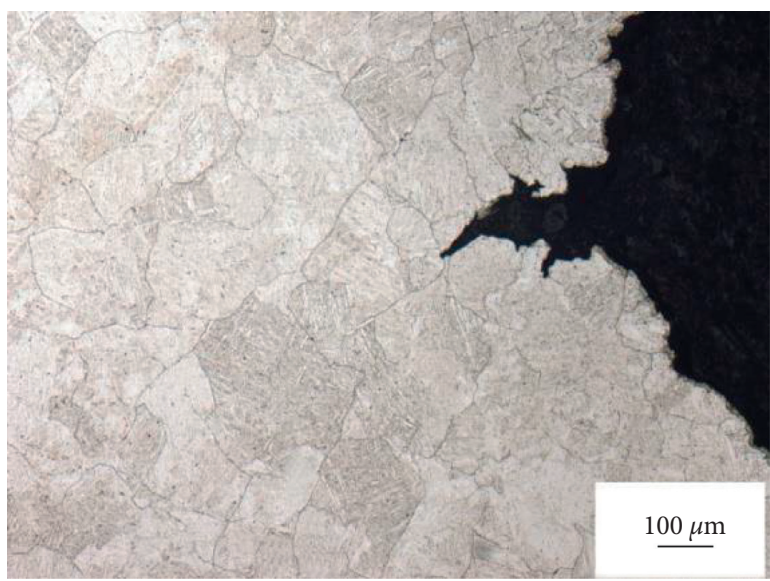

(a)

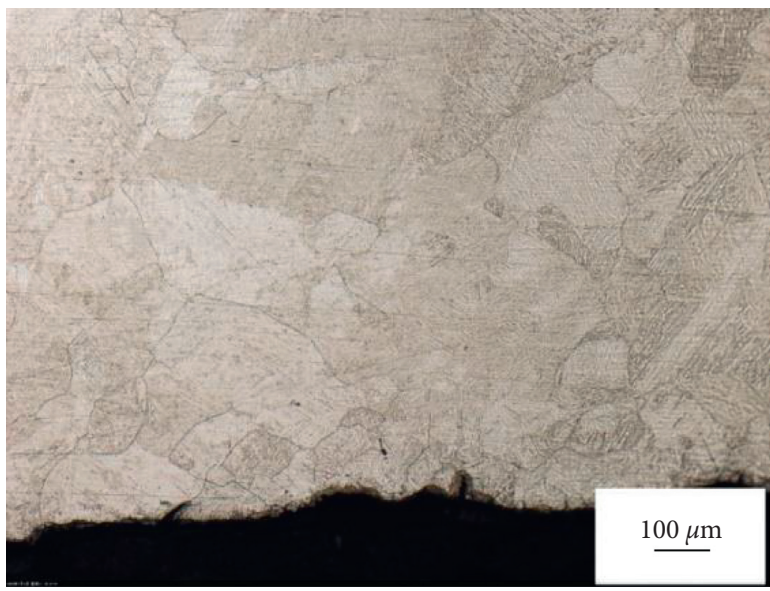

(c)

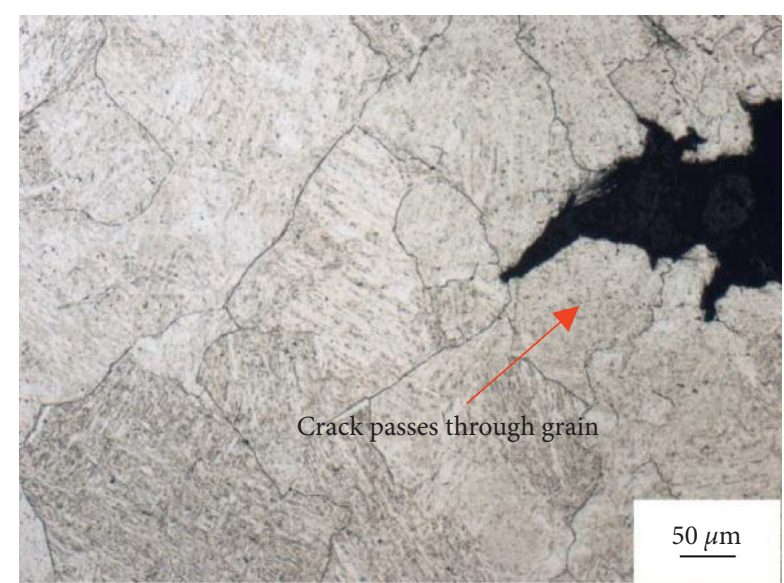

(b)

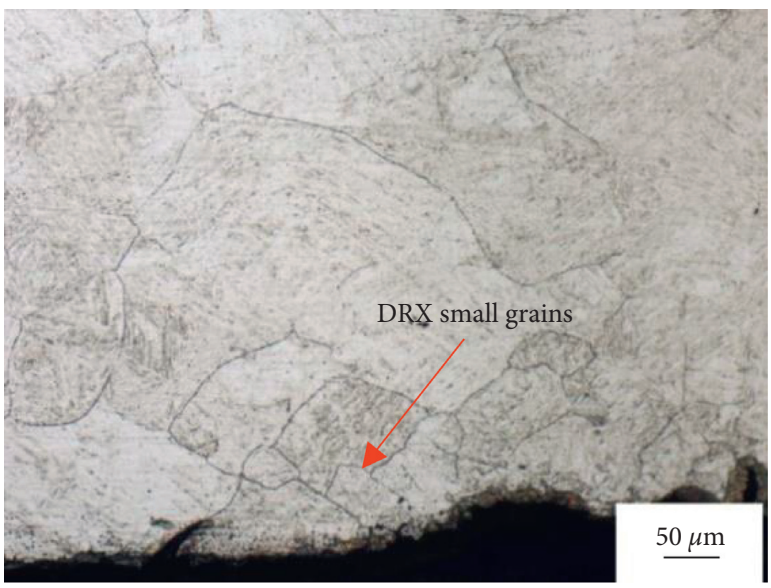

(d)

Figure 4: Microstructure of the crack healing zone at FR 1.1. (a, c) 100 times magnification. (b, d) 200 times magnification.

$30 \mathrm{Cr} 2 \mathrm{Ni} 4 \mathrm{MoV}$ steel, in addition to the microstructure change of the crack healing zone, the key point was to see the recovery of mechanical properties. In the latter part of this paper, the recovery of mechanical properties of materials is analyzed in detail.

\subsection{Tensile Properties and Fracture Morphology. Figure 9} shows the comparison of tensile properties between specimens with void and without void under the same deformation condition. Figure 9(a) presents the change in elongation with the increase of FR. When the FR was less than 1.8 , the elongation of the sample with void was less than $1 \%$, which indicated that the plasticity of the material had not been restored. At FR 2.0, the elongation after crack healing was $11.02 \%$, and the elongation of material without void was $11.27 \%$. The recovery rate of elongation was $97 \%$, which indicated that the internal crack disappeared and the elongation recovery was completed. When the FR increased to 2.2 , the elongation of the material after crack healing was $11.17 \%$, which was basically consistent with that of the matrix material. In the process of crack healing, the change of reduction of the area with deformation is shown in Figure 9(b). At different deformation, the change rule of reduction of the area with FR was basically the same as that of elongation. At FR 2.0, the reduction of the area after crack healing was $37.69 \%$, and the reduction of the area of the material without void was $39.29 \%$. The recovery rate of reduction of the area was $96 \%$. When the FR was 2.2 , the recovery rate of reduction of the area was $98 \%$. The reason was that the grains continue to grow after recrystallization, and the microstructure becomes more uniform in the crack healing zone.

With the increase of FR, the recovery of yield strength of the material in the crack healing zone is shown in Figure 9(c). When the FR was 1.8, the yield strength only recovered $58 \%$. As the FR increased to 2.0, the yield strength of the materials with and without voids was 1020.21 MPa and 1070.15 MPa, respectively. The recovery rate of yield strength was $97 \%$. At FR of 2.2, the yield strength of the material was $1009.86 \mathrm{MPa}$, which decreased by $60 \mathrm{MPa}$ compared with FR of 2.0. The reason was that the cracks had been completely healed due to DRX. With the increase of deformation, the grains began 


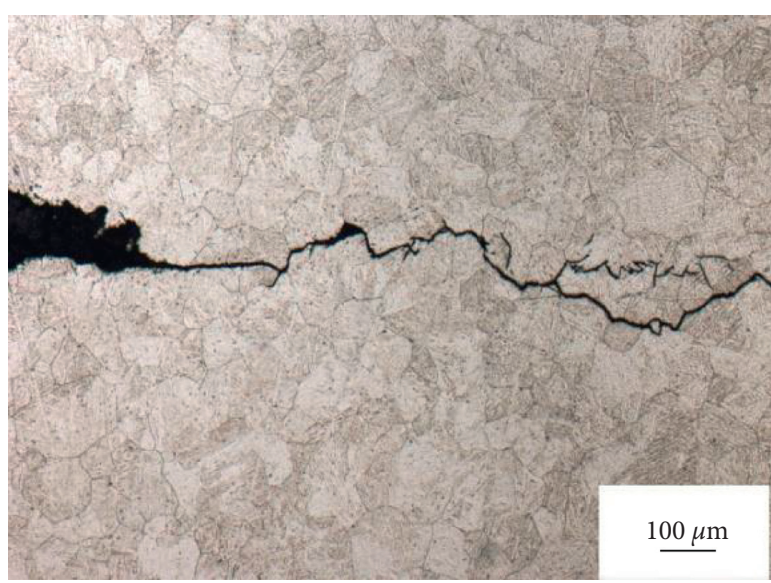

(a)

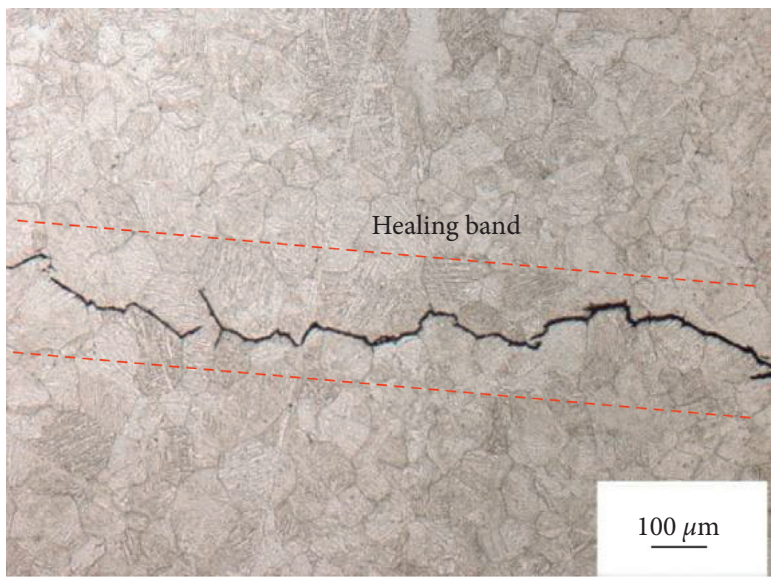

(c)

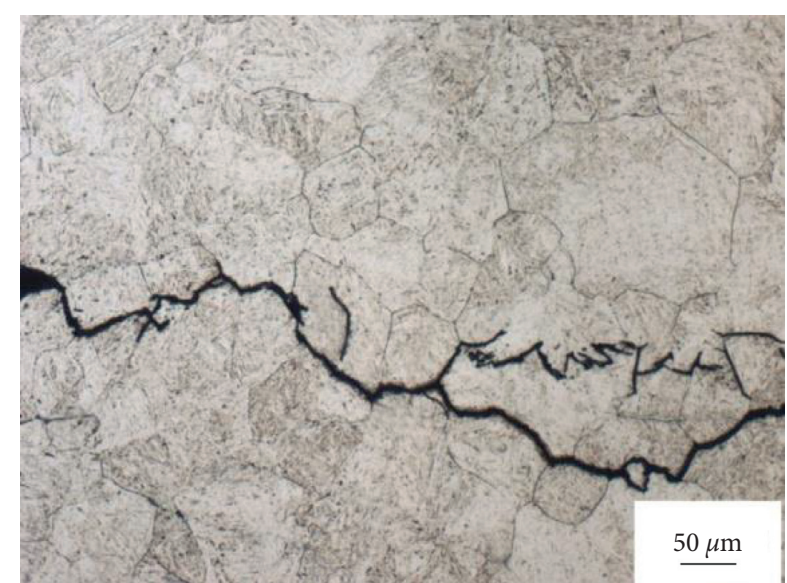

(b)

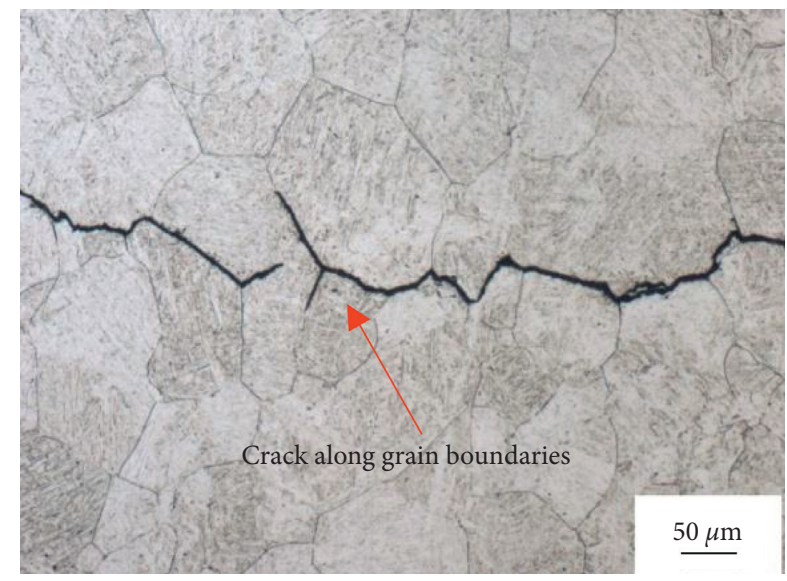

(d)

FIGURE 5: Microstructure of the crack healing zone at FR 1.5. (a, c) 100 times magnification. (b, d) 200 times magnification.

to grow and the yield strength decreased. Figure 9(d) shows the change of tensile strength in the crack healing zone at different values of FR. At FR 2.0, the tensile strength of the materials with and without voids was 1590.51 MPa and 1616.45 MPa, respectively. The recovery rate of tensile strength was $98 \%$. With the forging ratio increasing to 2.2 , the tensile strength basically did not change. Based on the above analysis, it can be seen that when the FR was increased to 2.0, the recovery rate of static load mechanical properties in the crack healing zone reached more than 95\%. Therefore, FR 2.0 can be considered as the best deformation condition for the recovery of static load mechanical properties.

The tensile properties of the crack healing zone did not recover when the FR was 1.1 and 1.5. Therefore, only the tensile fracture morphology after FR increased to 1.8 was analyzed. Figure 10 shows the tensile fracture morphology of the crack healing area after compression with different values of FR. As shown in Figure 10(a), the fracture morphology of the healing area was flat at FR 1.8. After local magnification, it can be found that small equiaxed dimples appeared in the healing area, and the area without healing was spherical convex morphology, as shown in Figure 10(b). When the FR increases to 2.0, the size and depth of equiaxed dimples gradually increased, as shown in Figures 10(c) and 10(d). At FR 2.2, the fracture morphology had little change. The above analysis showed that the microstructure and mechanical properties of the healing zone were basically restored at FR 2.0. This result is consistent with the law of tensile properties.

3.3. Impact Properties and Fracture Morphology. Figure 11 shows the variation of impact properties of specimens with and without voids after compression with different values of FR. When the FR was 1.1 and 1.5 , the impact energy of the material in the crack healing zone was $4 \mathrm{~J}$ and $8 \mathrm{~J}$, respectively. With the increase of deformation, the void began to close gradually and the impact energy increased gradually. At FR 1.8, the impact energy of materials with and without voids was $38 \mathrm{~J}$ and $68 \mathrm{~J}$, respectively. The recovery rate of impact energy was increased to $55.8 \%$. The reason was that, with the increase of deformation, the DRX volume fraction increased, and the healing degree of cracks also increased. However, because the void was not completely closed, the toughness was only half of the matrix material. As the FR increased to 2.2, the recovery rate of impact energy increased to $96.1 \%$. This indicated that the 


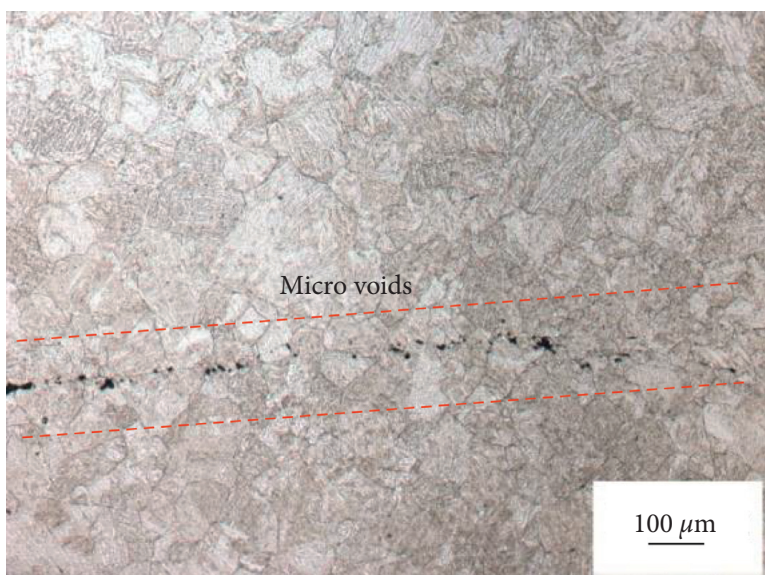

(a)

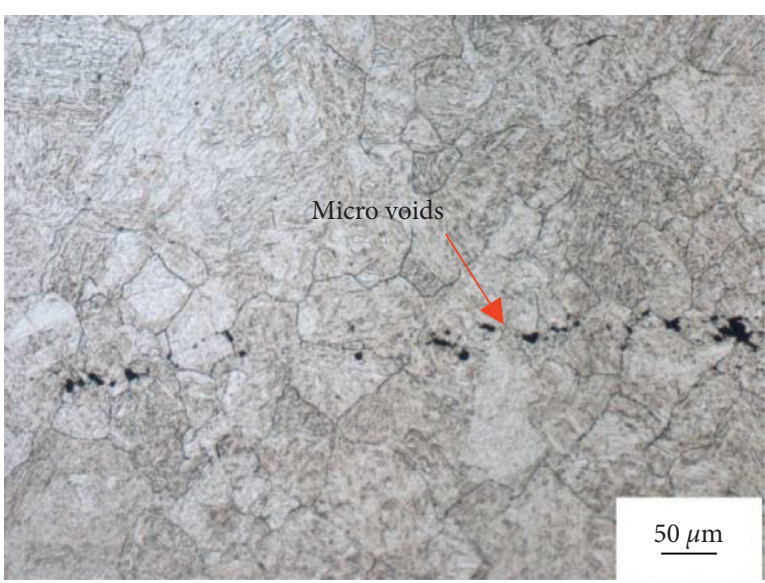

(b)

FIgURE 6: Microstructure of the crack healing zone at FR 1.8. (a) 100 times magnification. (b) 200 times magnification.

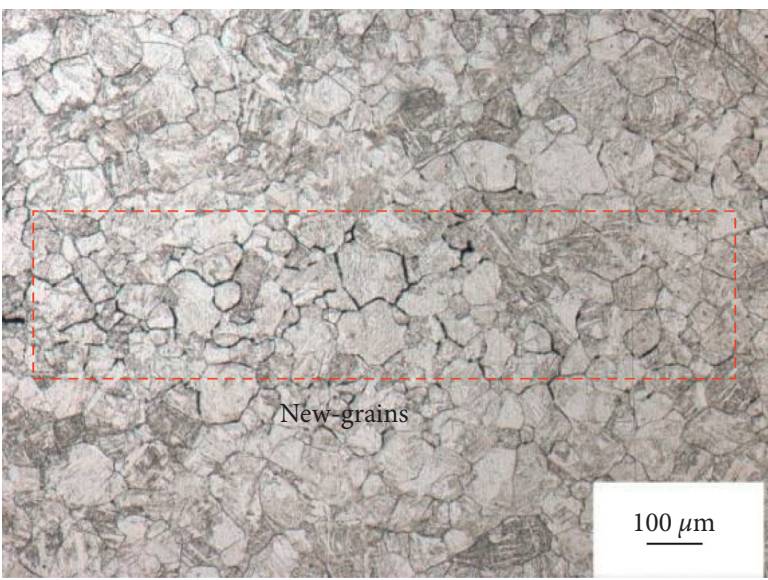

(a)

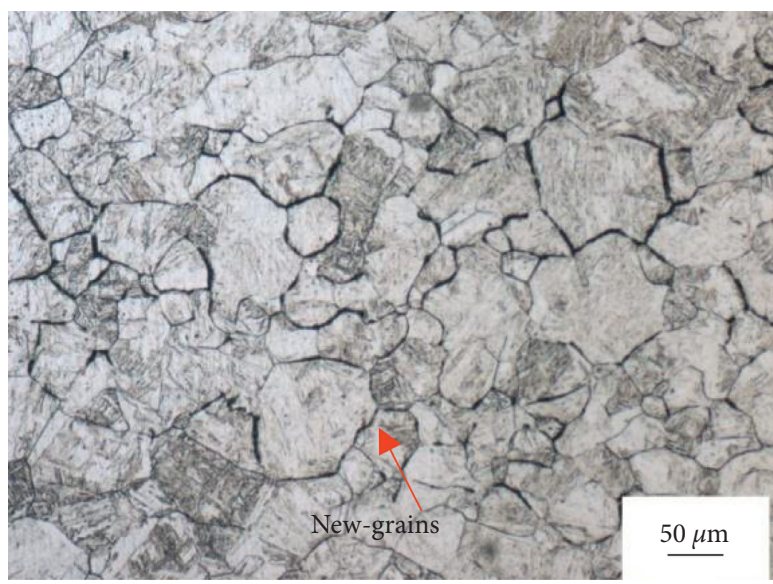

(b)

FIGURE 7: Microstructure of the crack healing zone at FR 2.0. (a) 100 times magnification. (b) 200 times magnification.

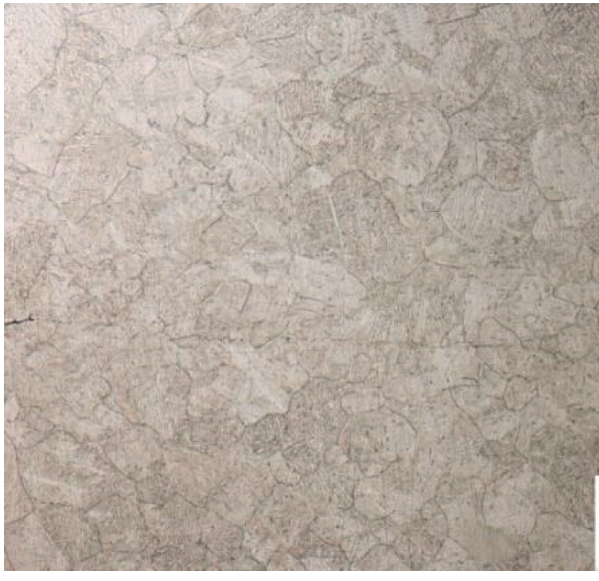

(a)

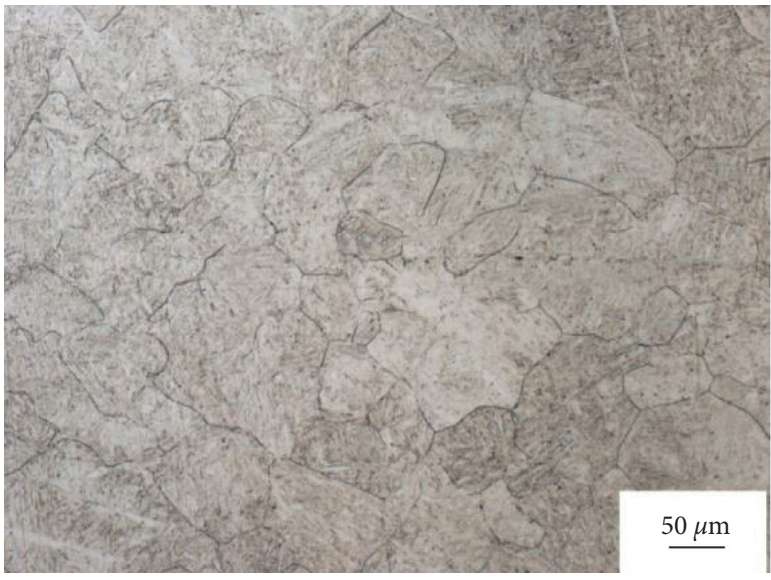

(b)

FIGURE 8: Microstructure of the crack healing zone at FR 2.2. (a) 100 times magnification. (b) 200 times magnification. 


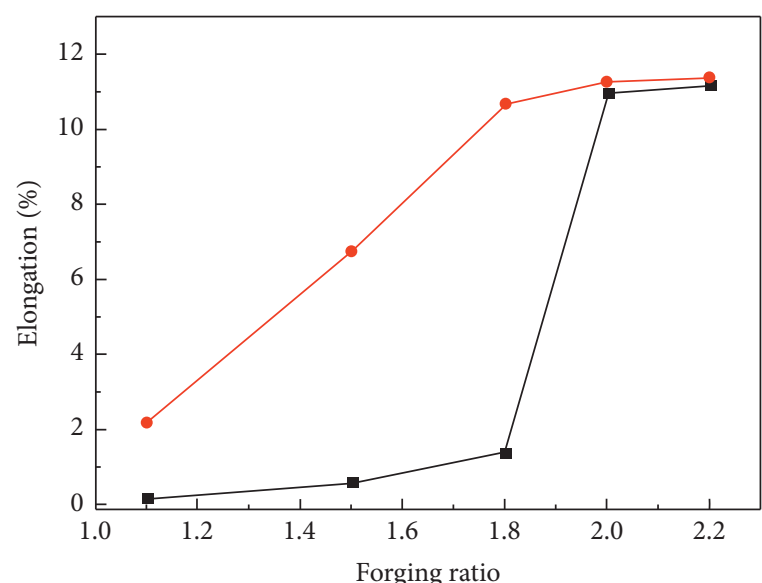

$\rightarrow-$ With void

$\rightarrow$ Without void

(a)

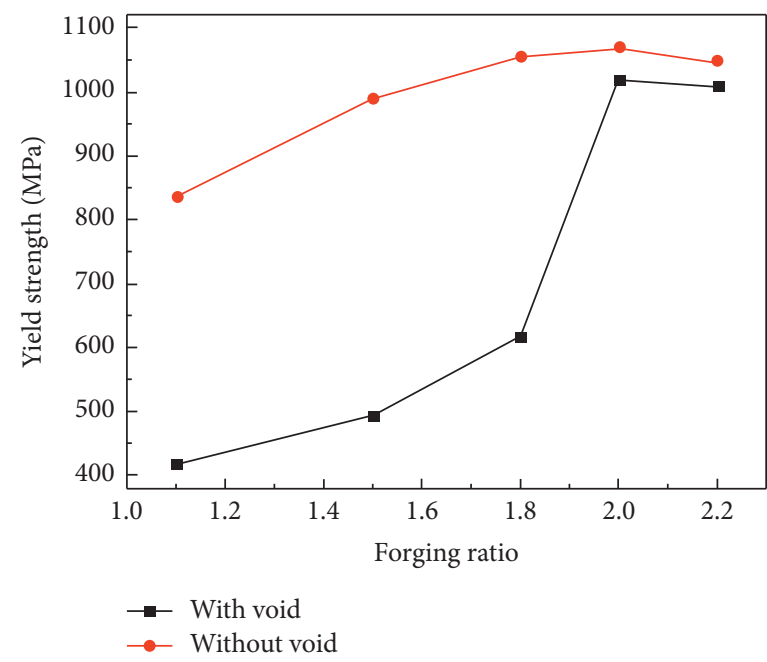

(c)

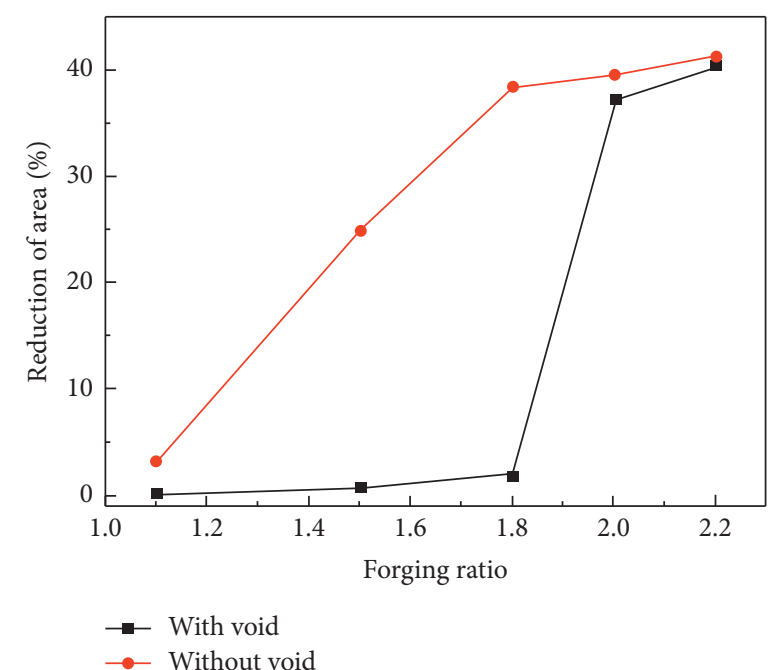

(b)

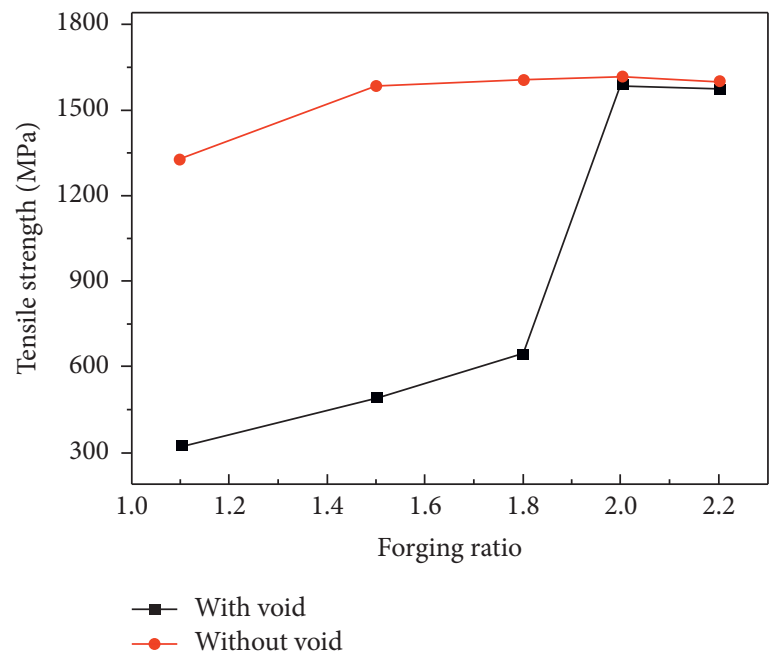

(d)

Figure 9: Changes of tensile properties in the crack healing area at different values of FR. (a) Elongation. (b) Reduction of the area. (c) Yield strength. (d) Tensile strength.

crack healing was basically completed, and the impact toughness had recovered to the level of the matrix material. When the FR continued to increase to 2.2, the impact energy began to decrease. This was due to the increase of forging time, and recrystallization grains had grown at high temperature. The impact toughness of the material was inversely proportional to the grain size. At this time, the grain size of the healing area increased, which reduced the value of impact energy.

Figure 12 shows the impact fracture morphology of the crack healing area under FR of 1.8, 2.0, and 2.2. As shown in Figure 12(a), there were many small dimples on the fracture surface. The reason was that a large number of fine recrystallized grains replaced the original cracks. Meanwhile, a large number of small microvoids were formed in the crack area, which formed a large number of small dimples under the impact load. At FR 2.0, the impact fracture morphology is shown in Figures 12(c) and 12(d). With the increase of deformation, the dimple size and dimple depth increased gradually. This was because the growth of recrystallized grains led to the disappearance of fine microvoids. When the impact load was applied, the microvoids grow into dimples again. At this time, the dimple depth increased and the dimple size increased. As the FR increased to 2.2, the morphology of impact fracture was mainly dimple, as shown in Figures 12(e) and 12(f). The results showed that the 


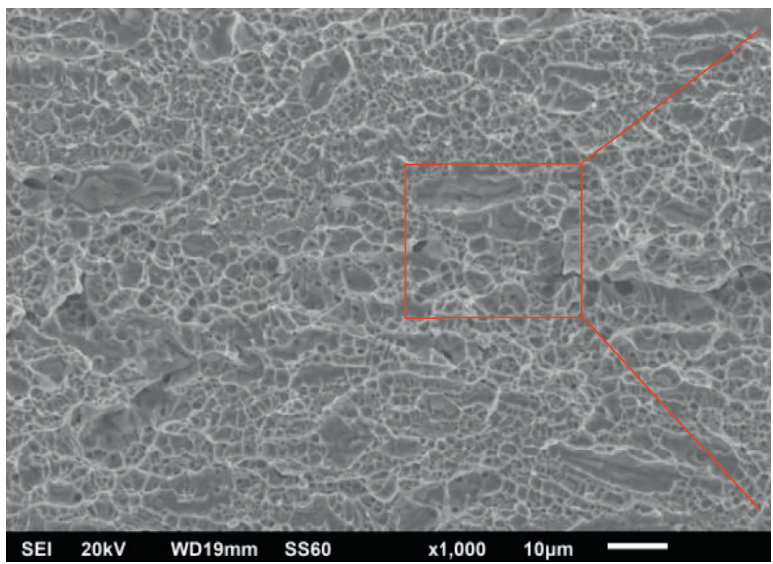

(a)

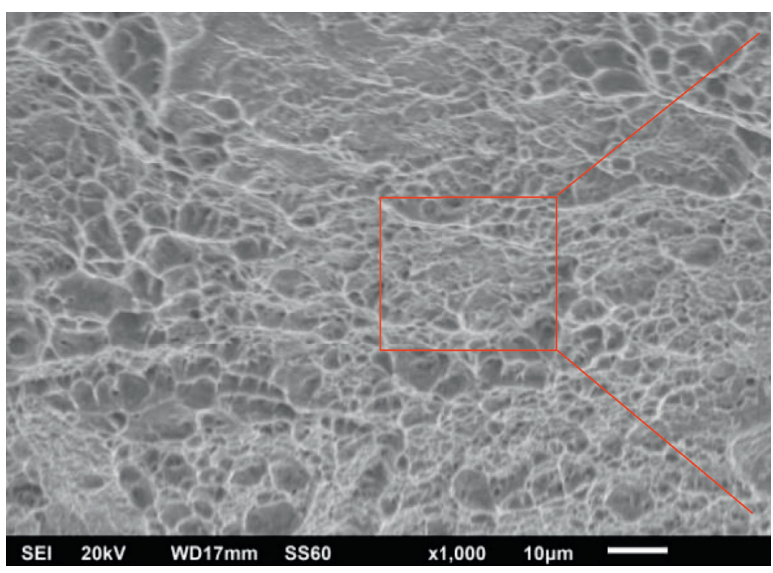

(c)

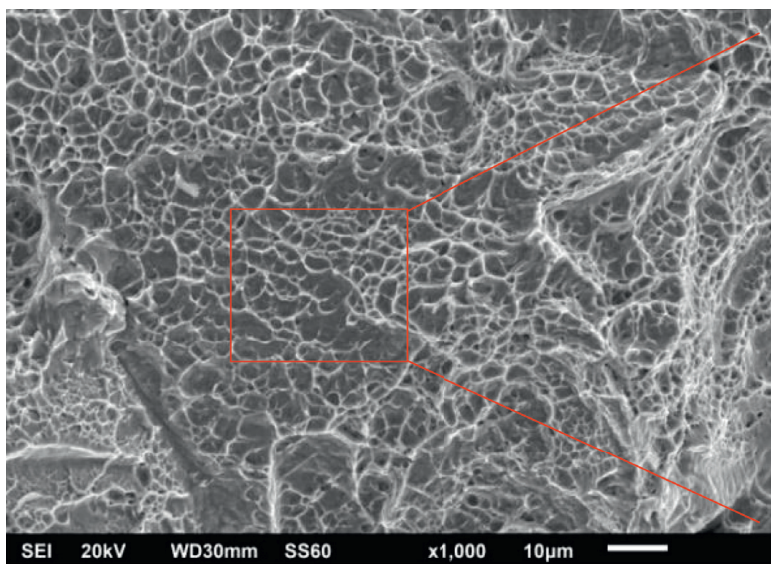

(e)

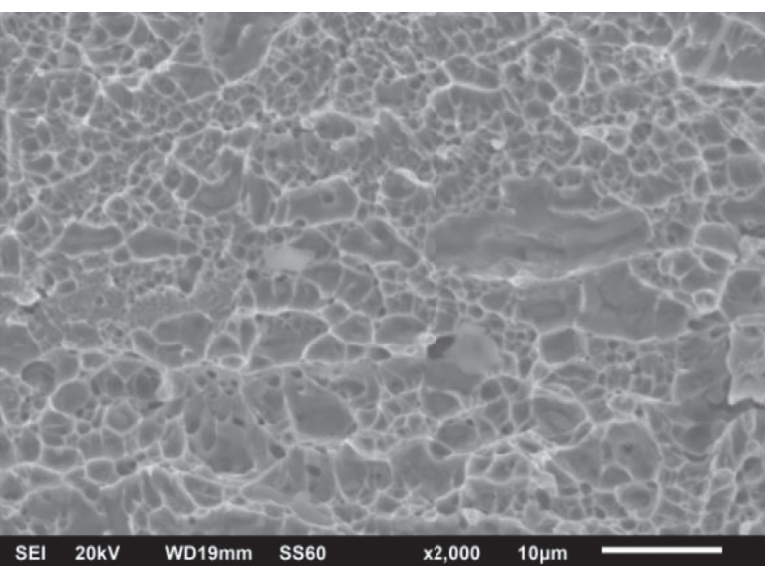

(b)

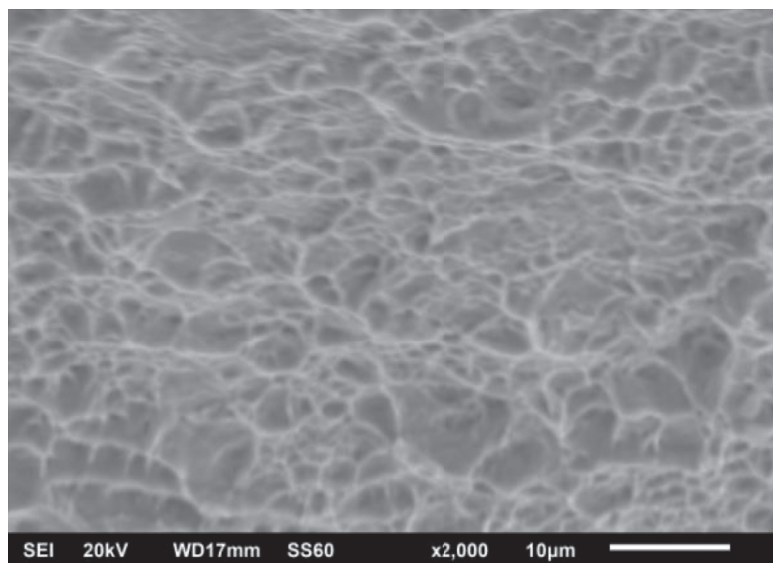

(d)

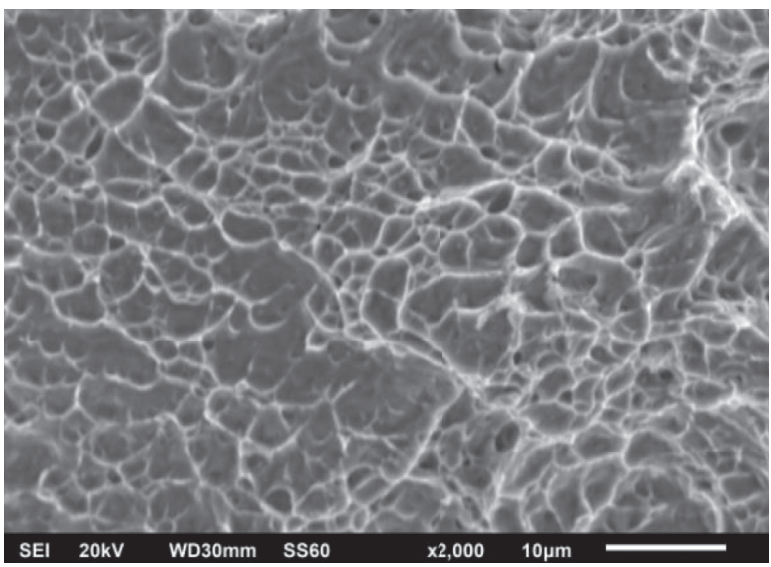

(f)

FIGURE 10: Tensile fracture morphology in the crack healing area at different values of FR. (a, b) FR of 1.8. (c, d) FR of 2.0. (e, f) FR of 2.2. 


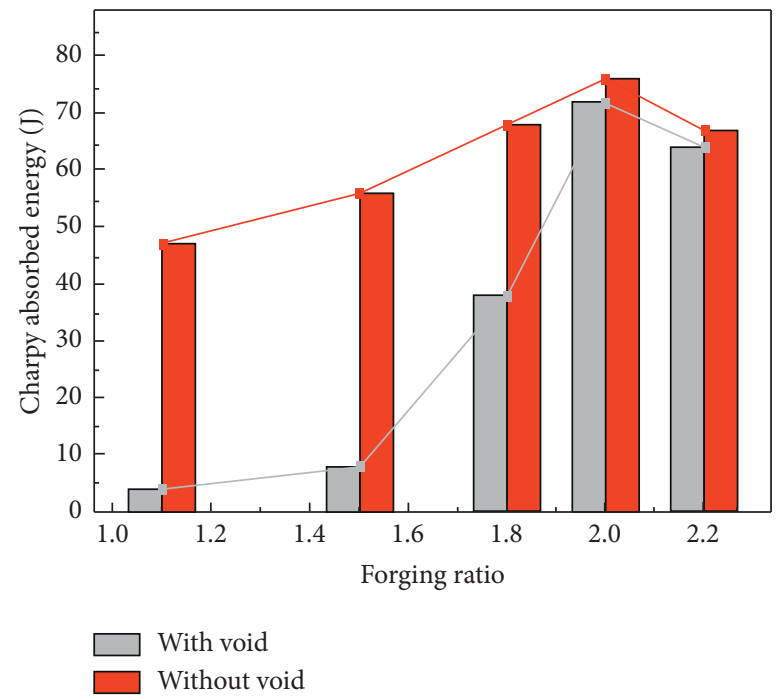

FIgURE 11: Changes of impact properties in the crack healing area at different values of FR.

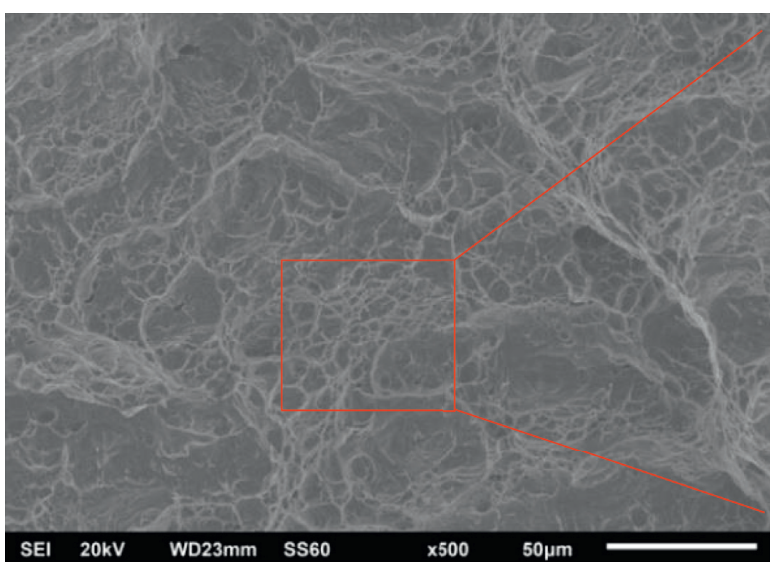

(a)

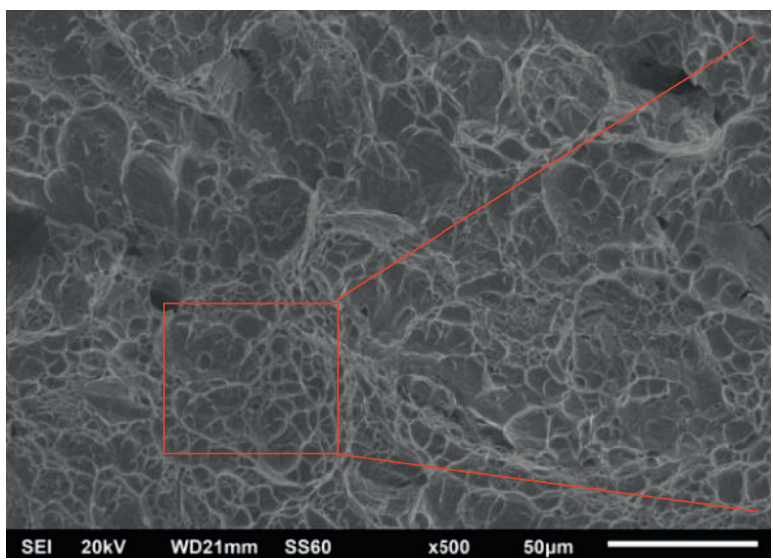

(c)

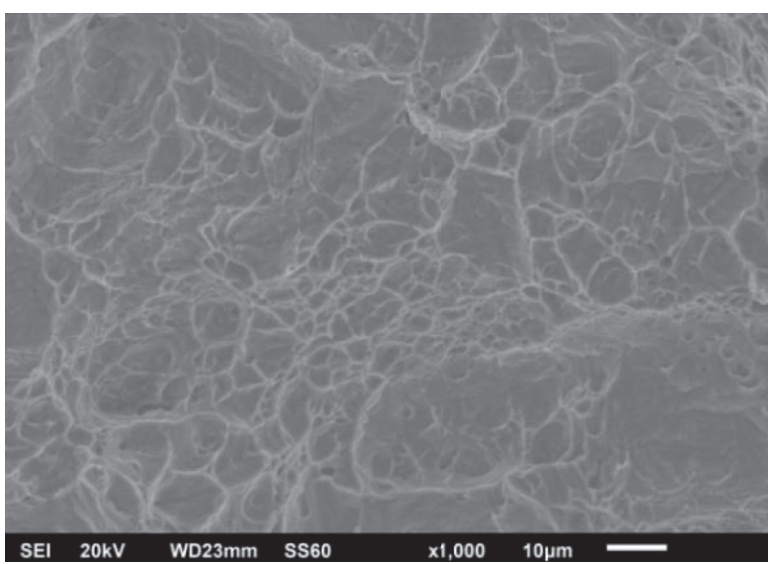

(b)

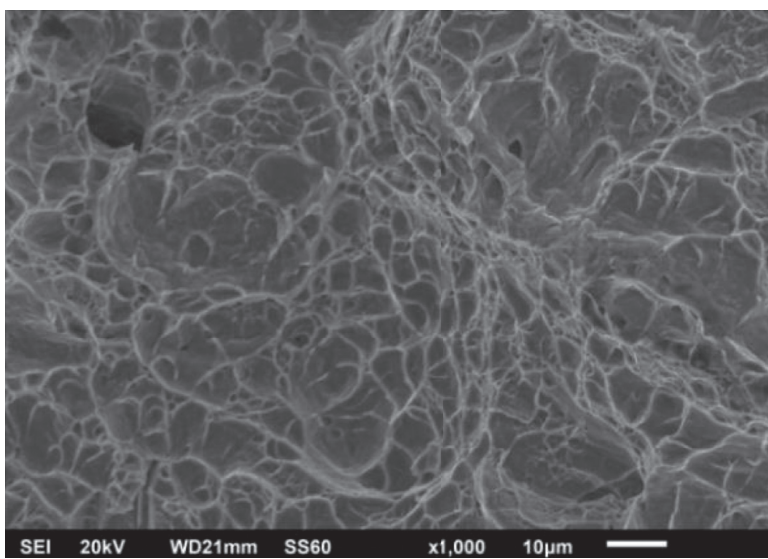

(d)

Figure 12: Continued. 


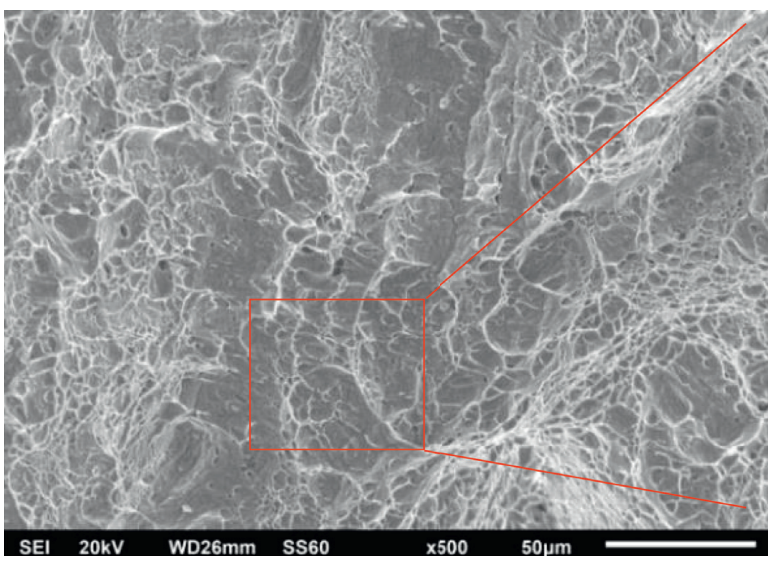

(e)

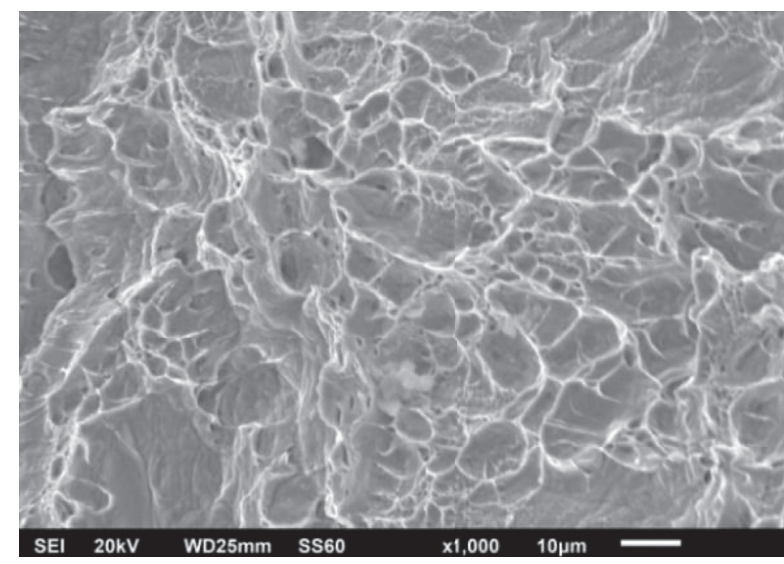

(f)

FIGURE 12: Impact fracture morphology in the crack healing area at different values of FR. (a, b) FR of 1.8. (c, d) FR of 2.0. (e, f) FR of 2.2.

material had plastic fracture. Furthermore, the impact energy of the crack healing zone had recovered to more than $95 \%$.

\section{Conclusions}

(1) When the FR was 1.5 , the crack at the sharp corner of the void began to heal. With the increase of FR, the volume fraction of DRX increased, which made the healing degree of cracks increase. At FR 2.2, the center crack was completely healed and the microstructure of the healing zone was very uniform.

(2) With the increase of deformation, the tensile properties of the crack healing zone gradually recovered. When the FR was 2.0, the recovery rate of plasticity and strength in the crack healing zone was above 95\%. At FR 2.2, the elongation increased slightly and the yield strength decreased slightly.

(3) When the FR was 2.0, the impact toughness recovery rate in the crack healing zone reached above $96 \%$. As the FR increased to 2.2, the grains grew up after recrystallization, which made the impact energy decrease slightly.

(4) The crack healing mechanism was that the grain growth made the microstructure uniform and played an important role in the plastic recovery. DRX and grain refinement played an important role in the recovery of strength and impact energy. Whether the internal crack was completely healed depended on the recovery of static tensile properties and dynamic impact properties to more than $95 \%$.

\section{Data Availability}

The data used to support the findings of this study are included within this article.

\section{Conflicts of Interest}

The authors declare that there are no conflicts of interest regarding the publication of this article.

\section{Acknowledgments}

The work was financially sponsored by the National Natural Science Foundation of China (51275330), Shanghai Dianji University, Shanghai Research Center of Engineering Technology for Large Parts Thermal Manufacturing, Project of Excellent Graduate Innovation in the Shanxi Province (2018BY102), and Scientific Research Foundation of Taiyuan University of Science and Technology (20192061).

\section{References}

[1] C. Feng, Z. Cui, M. Liu, X. Shang, D. Sui, and J. Liu, "Investigation on the void closure efficiency in cogging processes of the large ingot by using a 3-D void evolution model," Journal of Materials Processing Technology, vol. 237, pp. 371-385, 2016.

[2] A. Wang, P. F. Thomson, and P. D. Hodgson, "A study of pore closure and welding in hot rolling process," Journal of Materials Processing Technology, vol. 60, no. 1-4, pp. 95-102, 1996.

[3] K. Chen, Y. T. Yang, K. J. Liu, and G. J. Shao, "Simulation of void defect evolvement during the forging of steel ingot," Advanced Materials Research, vol. 97-101, pp. 3079-3084, 2010.

[4] Y. Zhou, J. Guo, M. Gao, and G. He, "Crack healing in a steel by using electropulsing technique," Materials Letters, vol. 58, no. 11, pp. 1732-1736, 2004.

[5] H.-L. Yu and X.-H. Liu, "Thermal-mechanical finite element analysis of evolution of surface cracks during slab rolling," Materials and Manufacturing Processes, vol. 24, no. 5, pp. 570-578, 2009.

[6] H. Yu, A. K. Tieu, C. Lu, and A. Godbole, "Investigation of closure of internal cracks during rolling by FE model 
considering crack surface roughness," The International Journal of Advanced Manufacturing Technology, vol. 75, no. 9-12, pp. 1633-1640, 2014.

[7] J. Li, Q. H. Fang, B. Liu, Y. Liu, Y. W. Liu, and P. H. Wen, "Mechanism of crack healing at room temperature revealed by atomistic simulations," Acta Materialia, vol. 95, pp. 291-301, 2015.

[8] C. L. Yang, H. J. Yang, Z. J. Zhang, and Z. F. Zhang, "Recovery of tensile properties of twinning-induced plasticity steel via electropulsing induced void healing," Scripta Materialia, vol. 147, pp. 88-92, 2018.

[9] H. Yu, X. Liu, X. Li, and A. Godbole, "Crack healing in a lowcarbon steel under hot plastic deformation," Metallurgical and Materials Transactions A, vol. 45, no. 2, pp. 1001-1009, 2014.

[10] B. Xie, M. Sun, B. Xu, C. Wang, D. Li, and Y. Li, "Dissolution and evolution of interfacial oxides improving the mechanical properties of solid state bonding joints," Materials \& Design, vol. 157, pp. 437-446, 2018.

[11] M.-S. Chen, Y. C. Lin, and K.-H. Chen, "Evolution of ellipticcylindrical and circular-cylindrical voids inside power-law viscous solids," International Journal of Plasticity, vol. 53, pp. 206-227, 2014.

[12] M.-S. Chen and Y. C. Lin, "Numerical simulation and experimental verification of void evolution inside large forgings during hot working," International Journal of Plasticity, vol. 49, pp. 53-70, 2013.

[13] H. L. Zhang and J. Sun, "Diffusive healing of intergranular fatigue microcracks in iron during annealing," Materials Science and Engineering: A, vol. 382, no. 1-2, pp. 171-180, 2004.

[14] H. Song and Z.-J. Wang, "Microcrack healing and local recrystallization in pre-deformed sheet by high density electropulsing," Materials Science and Engineering: A, vol. 490, no. $1-2$, pp. 1-6, 2008.

[15] A. Hosoi, T. Nagahama, and Y. Ju, "Fatigue crack healing by a controlled high density electric current field," Materials Science and Engineering: A, vol. 533, pp. 38-42, 2012.

[16] Y. J. Zhang and J. T. Han, "Analysis of microstructure of steel 20 in the range of healing of internal crack," Metal Science \& Heat Treatment, vol. 53, no. 11-12, pp. 526-528, 2012.

[17] R. Xin, Q. Ma, D. Guo, and W. Li, "Restoration of impact properties of internal crack healing in a low carbon steel," Materials Science and Engineering: A, vol. 682, pp. 433-440, 2017.

[18] Y. Qiu, R. S. Xin, J. B. Luo et al., "Crack healing and mechanical properties recovery in SA 508-3 steel," Materials, vol. 12, no. 6, 2019.

[19] L. J. Wang, L. Y. Sheng, and C. M. Hong, "Influence of grain boundary carbides on mechanical properties of high nitrogen austenitic stainless steel," Materials \& Design, vol. 37, pp. 349-355, 2012.

[20] R. Xin, Q. Ma, W. Li et al., "Microstructure and mechanical properties of internal crack healing in a low carbon steel," Materials Science and Engineering: A, vol. 662, pp. 65-71, 2016. 